\title{
A UTOPIA COOPERATIVISTA REGULADO PELO DIREITO: LEGITIMAÇÃO DO TRABALHO MORTO
}

\begin{abstract}
Marcos Rafael G. Gonçalves
Bacharel em Direito pela Universidade Federal do Paraná e mestrando pela mesma Universidade. Pesquisador do Núcleo do Direito Cooperativo e Cidadania e do Núcleo de Estudos Filosóficos do Programa de Pós Graduação em Direito da Universidade Federal do Paraná.
\end{abstract}

RESUMO: A crise e o esgotamento do modelo positivista do Direito é uma constatação há tempos compreendida e divulgada por juristas críticos das mais diferenciadas correntes. Aqui, a crise do modelo tradicional (hegemônico) do Direito é trabalhada a partir do Direito Cooperativo, na medida em que se constata a não correlação entre os sentidos ôntico e deôntico da norma. Se a legislação cooperativista vigente sistematicamente afronta contra os princípios que definem e caracterizam o cooperativismo (desnaturando a proposta dos trabalhadores de organizarem a produção em moldes não capitalistas), esse sistema de normas deve ser considerado como inválido, injusto e ilegítimo. A constatação e a tomada de consciência das negatividades geradas por esse sistema de totalidade aponta para a necessidade de elaboração de uma estratégia teórico-prática de superação desse estado de coisas. Dada a crise do positivismo jurídico, incapaz de dar respostas às demandas sociais num contexto de país periférico, faz-se necessário (re)construir o Direito em outras bases, construindo o saber o jurídico nos marcos de um projeto transmoderno.

PALAVRAS-CHAVE: Positivismo Jurídico; Direito Cooperativo; Cooperativismo; Crise - Transmodernidade 


\section{INTRODUÇÃO}

Este artigo tem o objetivo de discutir a insuficiência epistemológica da ciência jurídica tradicional em regular o fenômeno social denominado cooperativismo $\operatorname{popular}^{1}$ (pois é grande a distância entre a lei e o fato social) e partir dessa constatação trabalharmos numa perspectiva teórico-prática de constituição de um discurso jurídico transmoderno - estamos a tratar, em última análise da crise do positivismo jurídico.

Michel Miaille, em sua Introdução Crítica ao Direito, vai definir a "ciência" jurídica (tradicional) como o conhecimento sistemático das formas jurídicas². Demonstra o citado autor que, embora uma grande parte dos juristas não ouse em explicitamente defender seus pressupostos, a teoria formalista ${ }^{3}$ alcança o status de senso comum teórico, e dessa forma, "o conhecimento do direito identifica-se com a análise de uma construção hierárquica de normas que se engendram umas as outras". Mas, a teoria formalista do direito incorre num insanável paradoxo:

"De fato, por um curioso paradoxo, a escola formalista, que repudia qualquer incursão política ou filosófica, começa por estabelecer princípios que, na realidade, se apoiam numa filosofia do conhecimento muito particular. Em nome de uma separação nítida entre ciências da natureza e ciências morais que os juristas formalistas podem propor a autonomia da ciência jurídica" 5 .

Nessa perspectiva Plauto Faraco de Azevedo vai ensinar que "quer o positivismo que se veja o direito como ser em si, constituído de normas e de conceitos que se auto-explicariam, não admitindo nenhum juízo sobre a validade intrínseca ou sobre a legitimidade da fonte de que procedem"6. Dessa forma, em um exacerbado sentido ideológico, o positivismo não tem outra "razão de ser" que não a de assegurar a permanência da atual conjunção de forças no processo histórico, em detrimento de toda a dinamicidade e ousadia dos movimentos sociais organizados.

Da assimilação subordinada dessa forma de pensar e viver o Direito num contexto periférico do sistema-mundo capitalista, Antônio Carlos Wolkmer, constatando que o puro formalismo jurídico (o monismo estatal centralizador) desconsidera o funcionamento de uma sociedade concreta, vai defender a "crise e (...) esgotamento do modelo jurídico liberal-individualista, que não oferece respostas satisfatórias (eficazes) aos reclamos político-sociais de segurança e certeza no atual estágio de evolução das sociedades complexas e conflitivas de massas"7. 
Deve-se ficar claro que a questão que nos causa perplexidade é essa separação entre ser e dever-ser, entre ontologia e deontologia, no discurso jurídico e do direito. Nesse sentido o objetivo deste artigo é, então, desde a Teoria Geral do Direito (e tomando como exemplo o caso específico do Direito Cooperativo), indicar uma das possíveis causas dessa problemática, e no limiar, apontar caminhos para a reaproximação destas duas lógicas.

Iniciamos a exposição da problemática denunciando que o direito positivo (a legislação cooperativista vigente) não regula adequadamente 0 ente (cooperativismo) que deveria regular ${ }^{8}$. Em seguida passamos a discorrer, de forma sintética (já que esse não é o objetivo do texto), os pressuposto do positivismo jurídico e estabelecer a crítica a esses fundamentos, identificando o idealismo como uma das causas da desconexão entre as relações sociais e o referente do Direito. Por fim, na conclusão, teceremos, desde as premissas estabelecidas pelo paradigma da transmodernidade, algumas considerações sobre a necessidade de estabelecer um discurso jurídico genuinamente latino-americano, que tem na reaproximação entre ser e dever-ser um dos seus desafios centrais.

\section{REGULAÇÃO: A PASSAGEM DO SER PARA O DEVER-SER}

\subsection{Legitimidade do Direito Cooperativo}

O tratamento do cooperativismo ${ }^{9}$ na literatura jurídica, ou mais especificamente da sua regulação pelo Direito, é marcado por uma enorme imprecisão teórica. A falta de um tratamento ontológico consistente do cooperativismo traz como conseqüência lógica a existência na juridicidade, tanto no plano do discurso do Direito (enunciados normativos) quanto no plano do discurso jurídico (texto sobre os enunciados normativos), de um discurso que legitima e valida, no campo da faticidade, a presença de empreendimentos que, embora formalmente levem a alcunha de cooperativas, verdadeiras cooperativas não são ${ }^{10}$, pois negam determinados preceitos e princípios fundamentais do cooperativismo: gestão democrática, controle do processo de produção e distribuição do resultado proporcional ao trabalho realizado ${ }^{11}$. 
A legislação cooperativista brasileira, a despeito dos dispositivos constitucionais que vão determinar o apoio e estímulo ao cooperativismo (art.174, § $2^{\circ}$ da CF) e a proibição da interferência estatal no funcionamento da cooperativa (art. $5^{\circ}$, XVII, da CF), é fortemente voltada para afirmar a relação conflituosa entre a teoria cooperativista ${ }^{12}$ e o modelo positivista do Direito, uma vez que o Direito Positivo não regula adequadamente aquilo que se denomina cooperativismo/ cooperativas, pois no limiar acaba por negar um de seus fundamentos principais, qual seja, a autogestão.

É considerável (e irrefutável) o referencial teórico que permite identificar a Lei do Cooperativismo - Lei Federal 5.764/71 - diretamente atrelada ao interesse das elites agrárias de nosso país ${ }^{13}$, não sendo mera coincidência que as grandes cooperativas agrícolas são as expressões (e as grandes defensoras) do marco regulatório existente. O mais recente exemplo dessa falta de precisão teórica na regulação do cooperativismo no ordenamento jurídico brasileiro - verdadeira incoerência - é a disposição trazida pelo 'novo' Código Civil no tratamento do Direito de Empresa, quando, de forma extremamente confusa, vai indicar que a sociedade cooperativa seria espécie do gênero das sociedades simples (artigos 982, 983 e 1.096, CC). Comentadores desavisados, desde $\log ^{14}$, e sempre tomando a Lei como ponto de partida para tratar do movimento cooperativista, vão somar eco a essa postura adotada pelo "legislador" afirmando, por exemplo, que "Cooperativa. É uma associação sob forma de sociedade simples, com número de membros (...) É uma modalidade especial de sociedade simples (CC, art. 982, parágrafo único, in fine) sujeita a inscrição na Junta Comercial” ${ }^{\prime 15},{ }^{16}$.

Quando o Direito perde a vitalidade que Ihe devia ser característica e começa a apresentar-se sempre desconectado da realidade social, sempre defasado em relação ao desenvolvimento e mudança das estruturas sociais, ele passa a se configurar como um "obstáculo à transformação social"17. Quando o Direito não qualifica adequadamente o ser que deve regular, o sistema entra em crise:

"Por maior que seja - e mais bem sucedido - o esforço de legislador em bem apreender a realidade, sempre existe margem para equívocos, ou, ao longo do tempo, para alterações de realidade social que façam tornar-se superada a descrição normativa adequada. Quando a norma não mais qualifica adequadamente o ser que regula, o sistema entra em crise ${ }^{18, "}$. 
Pelo fato do estatuto jurídico do cooperativismo vigente no Brasil não corresponder ao que o cooperativismo é, ao que as cooperativas são, torna-se irrefutável que o Direito Cooperativo é um espaço privilegiado para que se comprove a denúncia feita por Eduardo Novoa Monreal em sua obra O Direito como obstáculo à transformação social: "Cada vez se faz mais perceptível o descompasso que existe entre o Direito e as realidades sociais que hoje o mundo experimenta"19.

É fundamentado nas contribuições desses dois autores latino-americanos, e ancorado em um juízo descritivo de verdade material ${ }^{20}$ sobre a regulação do cooperativismo no Brasil, que se (a)firma a crítica ao modelo do positivista do direito, com sua lógica formalista. A tese aqui defendida é que, face ao não reconhecimento dos princípios e objetivos do cooperativismo por parte do discurso jurídico e do Direito, como instituição que é, esta se mostra inválida, injusta e ilegítima ${ }^{21}$.

Aceitar a regulamentação do empreendimento cooperativo traçada nas formas legais constantemente (im)postas é aceitar o reinado de um Direito que não serve aos interesses das organizações sociais - pois, como conseqüência do "império da lei", não raro, tolhe-se das iniciativas populares toda a potencialidade e ousadia que Ihes são características (evidenciando, assim, que o congelamento dos fatos sociais é algo inerente ao "mundo jurídico") ${ }^{22}$.

\subsection{Crítica ao Positivismo Jurídico}

Norberto Bobbio, discorrendo sobre os pontos fundamentais da doutrina juspositivista, vai definir em sete as características fundamentais do positivismo jurídico ${ }^{23}$. Interessa-nos a determinação de que a característica fundamental na definição do Direito seria o critério formal, prescindindo de conteúdo, considerando apenas como o Direito se produz e não o que ele estabelece.

"Se desejarmos tentar precisar a característica fundamental das definições positivistas, veremos que está representada pelo fato de que as mesmas procuram estabelecer o que é o direito prescindindo de do seu conteúdo, vale a pena dizer, da matéria por este regulada; insto porque o conteúdo do direito é infinitamente variado"24.

Michel Miaille, criticando a auto-suficiência e todos os conhecimentos a priori do conhecimento jurídico, vai propor a existência de três "desafios epistemológicos" a serem superados pela ciência jurídica para que esta se constitua como 
"verdadeira"25. Na linha de nossa argumentação nos interessa a denúncia que é realizada acerca do "idealismo profundo das explicações jurídicas", uma vez que esse "idealismo" 26 pode ser identificado como uma das causas da desconexão entre as relações sociais e o referente do Direito.

O Idealismo, como corrente de pensamento de filosófico, estaria inserido no seio da ciência do direito de forma bem sutil - "os juristas não vão tão longe" -, uma vez que os juristas não precisam assumir uma posição filosófica bem definida ${ }^{27}$. $O$ idealismo no "mundo jurídico" se apresenta na operação (racionalidade lógicoformal) de considerar as noções de direito sempre apresentadas e tratadas fora de um contexto social preciso, como se a lei viesse antes dos fatos sociais, ou seja, a "ciência" jurídica subordina a realidade ao seu "sistema de pensamento". "Estes mecanismo intelectuais conduzem a resultados desoladores: os fenómenos, por vezes os mais evidentes, perdem-se, enquanto que as ideias se tornam 0 fundamento da realidade, ${ }^{, 28}$.

Afora isso, e em um sentido oposto da teoria positivista do direito, há que se destacar que as regras de direito, por nascerem de necessidades específicas de determinado agrupamento social em determinado momento histórico, não têm qualquer pretensão científica ("correspondem a necessidade de vida de sociedade"29): é cultural, histórica. Nesse sentido as leis, os Códigos etc são o resultado de uma escolha, um acordo, é uma convenção, e por isso mutáveis pode definição.

É nesse sentido que se pode afirmar que o caráter ideológico do discurso do direito. Plauto Faraco, em sua obra citada, assim vai definir ideologia como "o pensamento teórico que julga desenvolver-se abstratamente sobre seus próprios dados, mas que é, em verdade, expressão de fatos sociais, particularmente de fatos econômicos, dos quais aquele que a constrói não tem consciência, ou ao menos não se dá conta de que eles determinam o pensamento" ${ }^{\text {30 }}$. Nada mais apropriado para se refletir criticamente o Direito.

As regras jurídicas (tidas como gerais e abstratas), no atual estágio de desenvolvimento capitalista, não representam, pois, mais que uma imagem do mundo do direito (formalista e auto-referencial). Não têm, assim, qualquer pretensão explicativa. A ciência jurídica vai tomar como certa a imagem que Ihe transmite a sociedade e tomá-la pela realidade. "Toda a representação da vida social produzida 
pela sociedade se explica desde então por ela própria: uma noção implica outra e, nesse universo doravante totalmente coerente, tudo passa como num palco em que não se aparecem senão as personagens criadas pela ideologia social”"31. É assim que a ciência jurídica tradicional deve ser compreendida, como uma representação da vida social, não uma explicação, sendo esta representação intensamente idealista.

Por isso deve nos causar repulsa e estranhamento o pensamento jurídico realizado puramente a partir da lei e limitado somente a ela. É comum observar na literatura jurídica, no tratamento de um qualquer, a mera transcrição de textos de lei. Isso é bastante comum no tratamento do Direito Cooperativo brasileiro. Como já referenciado, comumente as cooperativas são tratas meramente a partir do que a legislação diz que elas são. É aí que a distancia entre o cooperativismo como fato e sua regulação pelo direito se impõe.

Uma vez assumidas as premissas do positivismo jurídico para se pensar e operar o Direito de pouco valeria a mudança do marco regulatório do cooperativismo no Brasil. Mudar a lei não é a solução. Como nos alerta Michel Miaille: "Nunca apanhado desprevenido, o jurista move-se no seu universo em qualquer idéia podendo a qualquer hora esta ser substituída, trabalhada, enriquecida ou actualizada por uma outra ideia mais apropriada"32. Assim, a ciência jurídica tradicional, confundindo a necessária abstração para compreensão e regulação dos fenômenos sociais, vai tomar as «idéias» de que nos fala Miaille (imagem, ideologia) e transformá-las em verdades, para a partir delas "explicar" a realidade. Enquanto a ciência do direito se resumir a enxergar o mundo a partir de seu próprio marco referencial - a partir de seu próprio umbigo - todas as legislações vigentes não terão outro sentido (pois esse é também o seu limite) de servir à função de ordenar e desordem e com isso ser um instrumento de dominação - em favor dos donos do poder e em detrimento de muitos (as vítimas).

Sendo idealista, o Direito é duvidoso que seus referentes estejam relacionados com fenômenos sociais concretos. Imposto ao mundo "civilizado" como "A" noção de direito a ser seguida, o paradigma tradicional do direito acabou por encobrir uma ampla diversidade de diferentes expressões do saberes jurídicos - é a soberba do projeto da modernidade, que numa racionalidade "eurocêntrica",33 
(conquistadora e violenta) vai causar o encobrimento do outro ${ }^{34}$ nos territórios pela racionalidade moderna subjugados.

"Esta aberração desmascara aqui a sua natureza: ao querer tomar o homem ocidental pelo Homem, e o direito ocidental pelo Direito, não se pode senão realizar uma «explicação» onde todas as particularidades são suprimidas em favor da Europa ocidental” ${ }^{\text {"35 }}$.

\section{CONCLUSÃO}

Com tudo o que foi exposto sobre a problemática da ciência jurídica hegemônica não ser capaz solucionar as demandas da sociedade carente de direitos percebe-se a necessidade de uma formulação teórica que trate conceitualmente da necessidade e possibilidade da aproximação entre a lógica do ser e do dever-ser, da necessidade e normatividade.

Dussel, em sua Ética da Libertação ${ }^{36}$ vai expor um ensinamento que é de grande valia para á ciência do direito, ou mais especificamente para a superação do paradigma jurídico vigente - na construção de projeto de libertação transmoderno. Propõe o autor argentino, desde uma fundamentação ético-filosófica, a reaproximação entre ser (ontologia) e dever-ser (deontologia). Embora muitos pensadores discordem dessa possibilidade, Dussel defende que tal proposta é factível, tendo sua condição de possibilidade na superação da lógica formal, afirmando uma lógica material (concreta, dialética).

Desde o paradigma da vida concreta torna possível (necessário) o estabelecimento de uma "práxis jurídica alternativa"37, que tem a exterioridade como ponto de partida, como fonte de justiça.

"Esta exigência de justiça identificada com os direitos dos oprimidos, como exterioridade (reserva permanente no interior das dominações) e fundamento de uma alternatividade jurídica deve incidir nos diferente planos já enunciados (nível da política, erótica, pedagógica, econômica...). Pois, em todos há uma negação de ser, dada a relação de dominação, porém, há também a afirmação analética em cada um dos níveis. A Justiça é, em cada um desses níveis concretos, a garantia de efetividade da exterioridade, negada na lógica da ontologia totalitária da identidade”38. 
Diante da crise e ineficácia da legalidade positivista em um contexto de subordinação político-econômico-cultural (na qual povos clamam por direitos) a ruptura desse sistema de totalidade (um Direito idealista afastado das concretas relações sociais) se impõe como necessidade, flertando com a construção de alternativa de um novo paradigma de produção normativa.

Esse novo paradigma jurídico a ser formatado onde haja sujeitos que gritam por efetividade de direitos (básicos) não poderá priorizar as regras técnico-formais e as ordenações genérico-abstratas, mas sim inspirar-se na práxis da vida cotidiana e na auto-regulação comprometida com a dignidade do outro injustiçado ${ }^{39}$.

No contexto atual da globalização, a precarização das condições de trabalho e o retrocesso efetuado com relação aos direitos sociais, tem sido exemplos de processos de vitimização e perda do protagonismo por parte da maior parcela da população do planeta.

No Brasil, a partir da década de 80 , é expressiva no meio urbano a quantidade de iniciativas populares que optam pela organização cooperativa como meio de se protegerem da exclusão social gerada pela reestruturação do sistema produtivo em escala mundial - trata-se, fundamentalmente, da questão do desemprego (hoje estrutural).

Ainda que a massa de despossuídos que nas cidades se organizam em unidades coletivistas de trabalho seja considerável ${ }^{1}$, a legislação brasileira até o momento não se deu conta desse pujante fenômeno social, uma vez que a legislação cooperativista vigente além de não considerar a existência desse grupo social muitas vazes acaba por se configurar como um obstáculo para o sucesso dos empreendimentos autogestionários. Assim, a atual legislação cooperativista mostrase defasada, pois incapaz de reconhecer a alteridade dos sujeitos cooperativos, desconsiderando o papel do cooperativismo (popular) como práxis de libertação o Direito se configura como um obstáculo à transformação social - o que é extremamente grave num Estado de incontestável papel indutor na redução de injustiças sociais - está se tratar de questão de Justiça social.

${ }^{1}$ Dados da Secretaria do Trabalho do Município de SP mostram que milhões de pessoas no Brasil organizam-se em formas de trabalho que não tem na relação capital-trabalho de tipo assalariado sua centralidade. 
Para a inclusão desses sujeitos que gritam por direitos, para serem ouvidos e reconhecidos, é necessários mudar a concepção que se tem do Direito. Por isso a necessidade de ruptura com o paradigma do positivismo jurídico para a construção de um outro projeto de vida, que vá além da sociabilidade proposta pela modernidade, num projeto que aqui denominamos de transmoderno.

\section{REFERÊNCIAS}

ARRUDA JÚNIOR, Edmundo Lima de. Direito Moderno e Mudança Social: ensaios de Sociologia Jurídica. Belo Horizonte, Del Rey , 1997.

BOBBIO, Norberto. O Positivismo Jurídico: Lições de filosofia do direito (compiladas por Nello Morra, tradução e notas Márcio Pugliese, Edson Bini, Carlos E. Rodrigues). São Paulo, Ícone, 1995.

CORRÊA DE OLIVEIRA, José Lamartine. A Dupla Crise da Pessoa Jurídica. São Paulo : Saraiva, 1979.

DINIZ, Maria Helena. Código Civil anotado. 10. ed. rev. e atual. de acordo com o novo Código Civil (Lei 10.406 de 10-1-2002). São Paulo Saraiva: 2004.

DUSSEL, E. Ética da Libertação: na Idade da globalização e exclusão. Petrópolis: Vozes, 2000.

FARIA, José Ricardo Vargas de. Organizações coletivistas de trabalho: Autogestão nas unidades produtivas. Dissertação de Mestrado. Universidade Federal do Paraná, Setor de Ciências Sociais Aplicadas: Curitiba, 2003.

FOUCALT, Michel. A verdade e as formas jurídicas. (Trad. Roberto Cabral de Melo Machado e Eduardo Jardim Morais, supervisão final do texto Léa Porto de Abreu Novaes... et al. J.). Rio de Janeiro, NAU Editora, 2003.

GONÇAVES, Marcos Rafael G. Da forma à função: a problemática da regulação das cooperativas no 'novo' Código Civil (Inédito). Mimeo.

LUDWIG, Celso. A alternatividade jurídica na perspectiva da libertação uma leitura a partir da filosofia da libertação de Enrique Dussel. Dissertação de Mestrado. UFPR: Curitiba, 1993.

MIAILLE, Michel. Introdução crítica ao Direito. 2. ed. Lisboa: Editorial Estampa, 1994.

MONREAL, Eduardo Novoa. O Direito como obstáculo à transformação social. Porto Alegre: Sérgio Antônio Fabris Editor, 1988.

WOLKMER, Antônio Carlos. Pluralismo jurídico: fundamentos de uma nova cultura no direito. São Paulo: Editora Alfa-Ômega, 2001. 
1 O sintoma é a constatação do verdadeiro abismo existente entre ser e dever-ser, entre o cooperativismo desenvolvido pelos trabalhadores nas organizações coletivistas de trabalho e o "cooperativismo" normativamente tratado pelo discurso do direito. Certamente está a se tratar de coisas (seres) distintas.

${ }^{2}$ MIAILLE, Michel. Introdução crítica ao Direito. 2. ed. Lisboa: Editorial Estampa, 1994. p. 298

${ }^{3}$ Que tem sua construção teórica mais consistente nos escritos de Hans Kelsen: teoria normativista.

${ }^{4}$ MIAILLE, Michel. op. cit. p. 299

"Acreditar que possa estudar um mundo de puras formas, sem nunca se referir aos conteúdos socioeconómicos, de que elas são expressão é pura ilusão para os juristas mais honestos ou pura hipocrisia para os juristas que conhecem as realidades que as formas escondem". P. 298

${ }^{5}$ Idem. op. cit. p. 300. O autor vai definir o Positivismo como uma corrente do pensamento, uma atitude epistemológica geral. p. 42-43.

${ }^{6}$ AZEVEDO, Plauto Faraco de. Crítica à hermenêutica e a dogmática jurídica. Rio Grande do Sul: Sérgio Antônio Fabris Editor, 1989. p. 24.

${ }^{7}$ WOLKMER, Antônio Carlos. Pluralismo jurídico: fundamentos de uma nova cultura no direito. São Paulo: Editora Alfa-Ômega, 2001. p. XVI.

${ }^{8}$ A referência é ao ensinamento do professor Lamartine, adiante citado.

${ }^{9}$ Tal como assevera José Henrique Faria a respeito do termo democracia não que se adjetivá-la, uma vez que ela simplesmente existe ou não existe (palestra proferida no Evento "E Experiência Cooperativista de Mondragón: lições e desafios para o Brasil", realizado nos dias 30 de Setembro e 01 de Dezembro de 2004, na Faculdade de Direito da Universidade Federal do Paraná). Da mesma maneira defendemos que não há que se adjetivar o termo cooperativismo, pois ele simplesmente é ou não é, não havendo meio termo - ou estamos tratando de cooperativas ou de uma firma capitalista (ou fraude).

Mesmo sabendo - e na verdade justamente por isto - que o conceito de cooperativas é algo ainda "em disputa", e que no senso comum - e nisto a legislação cooperativista vigente tem grande responsabilidade - por cooperativas se têm em mente as "cooperativas sob o comando do capital" (vide referência à dissertação de Daniele Pontes) - verdadeiras empresas capitalistas - e as cooperfraudes.

Nessa perspectiva, evitar-se-á o uso de expressões como "legítmo" ou "verdadeiro" cooperativismo. fraudes.

${ }^{10}$ As cooperativas sobre o comando do capital (que são verdadeiras empresas capitalistas) e as cooper-

11 FARIA, José Ricardo Vargas de. Organizações coletivistas de trabalho: Autogestão nas unidades produtivas. Dissertação de Mestrado. Universidade Federal do Paraná, Setor de Ciências Sociais Aplicadas: Curitiba, 2003.

12 Expressão da realidade (verdadeira necessidade) dos excluídos se organizarem em organizações coletivistas de trabalho - as cooperativas.

${ }^{13}$ Vide para tanto o básico O que é cooperativismo? - Coleção Primeiros Passos.

${ }^{14}$ Como nos ensina Michel Miaille.

${ }^{15}$ DINIZ, Maria Helena. Código Civil anotado. 10. ed. rev. e atual. de acordo com o novo Código Civil (Lei 10.406 de 10-1-2002). São Paulo Saraiva: 2004. p. 766.

${ }^{16}$ Sobre a problemática da regulação das "sociedades cooperativas" disposta no novo Código Civil e a afronta dessa disciplina legal aos princípios cooperativistas vide o nosso Da forma à função: a problemática da regulação das cooperativas no 'novo' Código Civil (Inédito) a ser publicado em breve.

${ }^{17}$ MONREAL, Eduardo Novoa. O Direito como obstáculo à transformação social. Porto Alegre: Sérgio Antônio Fabris Editor, 1988.

18 CORRÊA DE OLIVEIRA, José Lamartine. A Dupla Crise da Pessoa Jurídica. São Paulo : Saraiva, 1979. p. 607.

${ }^{19}$ Idem. op. cit. p. 9.

${ }^{20}$ DUSSEL, E. Ética da Libertação: na Idade da globalização e exclusão. Petrópolis: Vozes, 2000.

${ }^{21}$ Mais uma vez a referência à obra citada de Enrique Dussel. 
${ }^{22}$ Mas esta é a marca do Direito moderno, o que deixa claro que o que está por detrás desta discussão técnica é uma escolha: e entre a Justiça e segurança o Direito (com sua pretensão de congelar a realidade social para controlá-la ) prefere-se, sempre, a segunda.

${ }^{23}$ BOBBIO, Norberto. O Positivismo Jurídico: Lições de filosofia do direito (compiladas por Nello Morra, tradução e notas Márcio Pugliese, Edson Bini, Carlos E. Rodrigues). São Paulo, Ícone, 1995. p. 131-134.

1) a teoria da validade do direito, também conhecida como a teoria do formalismo jurídico; 2) a teoria da coatividade do direito; 3) a teoria da legislação como fonte proeminente do direito, 4) a teoria da norma jurídica (teoria imperativista do direito); 5) a teoria da coerência e completude; 6) a teoria da interpretação mecanicista e 7) a teoria da obediência absoluta da lei enquanto tal.

${ }^{24}$ Idem. op. cit.. p. 145

25. MIAILLE, Michel. op. cit. p. 33-62

26 "O segundo obstáculo epistemológico assume a figura de idealismo. Este obstáculo não pertence aos estudos jurídicos, mas assume aí um relevo muito particular”. MIAILLE, Michel. op. cit. p. 46.

${ }^{27}$ Idem. op. cit.. p. 47. Afinal, objeto de estudo dos juristas é lei, filosofia não lhes dizem respeito.

${ }^{28}$ Idem. Ibidem.

${ }^{29}$ Idem. op. cit.. p. 45. "Como escrevia um sociólogo no princípio deste século «Durkheim», usamos noções nascidas da prática e conferimos-Ihes um valor que elas não tem, acreditando que, por serem habituais e estarem largamente difundidas são verdadeiras. Daí a utilizá-las numa investigação dita científica vai um grande passo. Ele é largamente dado pelos positivistas. No fundo, estes, tomando as coisas tal qual elas são - ou como parecem ser - constroem, ainda que o neguem, todo o seu edifício de conhecimento vulgar e acabam por lhe dar estatuto científico".

${ }^{30}$ AZEVEDO, Plauto Faraco de. op. cit. p. 21, com apud em André Laland. Vocabulaire technique et critique de la philosophie. 10. ed. rev. aug. Paris: Press Universitaires de France, 1968. p. 459.

${ }^{31}$ MIAILLE, Michel. op. cit. p. 50-51

${ }^{32}$ Idem. op. cit. p. 52.

${ }^{33}$ Hoje os estadunidense.

${ }^{34}$ DUSSEI, Enrique. 1492: o encobrimento do outro: a origem do mito da modernidade: Conferências de Frankfurt (trad. Jaime A. Clasen). Petrópolis, RJ: Vozes, 1993.

${ }^{35}$ MIAILLE, Michel. op. cit. p. 54.

${ }^{36}$ Op. cit.

${ }^{37}$ LUDWIG, Celso. A alternatividade jurídica na perspectiva da libertação uma leitura a partir da filosofia da libertação de Enrique Dussel. Dissertação de Mestrado. UFPR: Curitiba, 1993.

${ }^{38}$ LUDWIG, Celso. op. cit. p. 141.

${ }^{39}$ A defesa de Wolkmer em sua obra citada. p. XXI. 